\title{
ADSORPSI LOGAM SENG DAN TIMBAL PADA LIMBAH CAIR INDUSTRI KERAMIK OLEH LIMBAH TANAH LIAT
}

\author{
Cindy Rianti Priadi ${ }^{*}$, Anita, Putri Nilam Sari, dan Setyo Sarwanto Moersidik \\ Program Studi Teknik Lingkungan, Departemen Teknik Sipil, Fakultas Teknik, Universitas Indonesia \\ Kampus Baru Universitas Indonesia, Depok, Indonesia 16424 \\ ${ }^{*}$ Penulis korespondensi: cindy.priadi@eng.ui.ac.id
}

\begin{abstract}
ADSORPTION OF ZINC AND LEAD FROM CERAMIC WASTEWATER USING CLAY. Ceramic industry generates glaze wastewater and clay waste. Glaze wastewater contains heavy metal from ceramic painting process which can potentially cause severe pollution problem. Glaze wastewater from PT.X typically contains $C d(0.013 \mathrm{mg} / \mathrm{L}) ; \mathrm{Cu}(0.033 \mathrm{mg} / \mathrm{L}) ; \mathrm{Pb}(1.20 \mathrm{mg} / \mathrm{L})$; and $\mathrm{Zn}$ $(7.00 \mathrm{mg} / \mathrm{L})$. Clay waste used as adsorbent to reduce heavy metal amount in glaze wastewater. The present study investigates in bench scale and uses batch adsorption method to determine effective adsorbent amount and contact time in removing heavy metals in glaze wastewater in order to fulfill the discharge requirement based on regulation of Minister of Environment No.16/2008concerning effluent water standard for ceramic industries. The results showed that the effective adsorbent amount and contact time respectively are $5 \mathrm{~g} / \mathrm{L}$ and 15 minutes with $\mathrm{pH} 8$ and stirring speed of $150 \mathrm{rpm}$. Concentration of heavy metal adsorbed are $0.614 \mathrm{mg} / \mathrm{L}$ and $2.07 \mathrm{mg} / \mathrm{L}$ for lead $(\mathrm{Pb})$ and zinc $(\mathrm{Zn})$ with removal efficiency up to $61.0 \%$ for $\mathrm{Pb}$ and $9.8 \%$ for Zn.From this study clay waste could be potentially used as an adsorbent to reduce heavy metal amount in glaze wastewater.
\end{abstract}

Keywords: adsorption; clay waste; heavy metals

\begin{abstract}
Abstrak
Industri keramik menghasilkan limbah glasir dan limbah tanah liat. Limbah glasir mengandung logam berat yang berasal dari proses pewarnaan keramik dan berpotensi mencemari lingkungan. Kandungan logam berat pada limbah glasir PT.X yaitu Cd (0,013 mg/L); Cu (0,033 mg/L); Pb (1,20 $\mathrm{mg} / \mathrm{L})$; dan $\mathrm{Zn}(7,00 \mathrm{mg} / \mathrm{L})$. Limbah tanah liat digunakan sebagai adsorben yang berguna mengurangi kadar logam berat pada limbah glasir.Penelitian ini dilakukan dalam skala laboratorium menggunakan metode batch adsorpsi untuk menentukan dosis adsorben dan waktu kontak yang efektif dalam mengolah limbah glasir agar memenuhi persyaratan Peraturan Menteri Negara Lingkungan Hidup Nomor 16 Tahun 2008 tentang baku mutu air limbah bagi usaha dan/atau kegiatan industri keramik. Hasil penelitian menunjukan dosis efektif adsorben sebesar $5 \mathrm{~g} / \mathrm{L}$ dan waktu kontak 15 menit dengan kondisi pH 8 dan kecepatan pengadukan 150 rpm. Kadar logam setelah diadsorpsi telah mencapai baku mutu yaitu sebesar 0,614 mg/L dan 2,07 mg/L untuk $\mathrm{Pb}$ dan $\mathrm{Zn}$ dengan efisiensi pengurangan kadar logam $\mathrm{Pb}$ sebesar 61\% dan $\mathrm{Zn}$ sebesar 9,8\%. Dari hasil penelitian didapatkan data bahwa limbah tanah liat berpotensi dijadikan adsorben untuk mengurangi kandungan logam pada limbah cair industri keramik.
\end{abstract}

Kata kunci : adsorpsi; limbah tanah liat; logam berat

How to Cite This Article: Priadi, C.R., Anita, Sari, P.N., dan Moersidik, S.S., (2014) Adsopsi Logam Seng dan Timbal pada Limbah Cair Industri Keramik oleh Limbah Tanah Liat, Reaktor, 15(1), 10-19, http://dx.doi.org/ 10.14710/reaktor.15.1.10-19

\section{PENDAHULUAN}

Perkembangan industri yang pesat menjadi salah satu penyebab meningkatnya fluks zat logam di dalam lingkungan. Hal ini mengkhawatirkan karena logam berat bersifat tidak terurai dan persisten. Paparan kontaminasi logam berat yang hadir, meskipun dalam konsentrasi rendah di lingkungan, dapat menjadi berbahaya bagi kesehatan manusia (Jain, 2004). Timbal (Pb) bersifat non-biodegradable di lingkungan dan dapat mengakumulasi terutama pada tulang, otak, ginjal dan otot serta dapat menyebabkan beragam kelainan seperti anemia, 
penyakit ginjal, gangguan saraf, mual bahkan kematian (Sahu dkk., 2013). Seng (Zn) dapat menyebabkan dehidrasi, ketidakseimbangan elektrolit, sakit perut, mual dan pusing (Veli dan Alyuz, 2007).

Dalam penelitian ini, larutan yang diambil berasal dari limbah glasir industri keramik. Dalam proses pengglasiran, bahan mentah yang digunakan terdiri dari bahan pembentuk, pelebur, pengental dan pewarna. Logam timbal dan seng biasanya ditemukan pada bahan pelebur yang digunakan dalam bentuk timbal oksida $(\mathrm{PbO})$ dan seng oksida $(\mathrm{ZnO})$ (Sundari, 2009). Logam-logam yang dipakai sebagai glasir berpotensi mengkontaminasi badan air apabila tidak diolah secara tepat.

Berbagai macam teknologi telah dikembangkan untuk menyisihkan logam berat dari air limbah. Teknik konvensional yang biasanya digunakan adalah proses fisik-kimiawi, seperti presipitasi, oksidasi, reduksi, ekstraksi pelarut, ekstraksi elektrolisis, penguapan, osmosis, pertukaran ion dan adsorpsi (Jang-Soon dkk., 2010). Reverse osmosis meskipun sangat efektif, merupakan proses yang membutuhkan biaya yang besar. Presipitasi kimia tidak cocok digunakan jika polutan yang hadir dalam jumlah banyak dan juga akan menghasilkan banyak lumpur dalam proses ini. Proses adsorpsi merupakan salah satu metode yang paling sering dilakukan untuk penyisihan logam beracun dalam air limbah (Mahitti, 2008). Adsorpsi merupakan proses fisik-kimiawi dimana adsorbat, dalam hal ini pencemar, terakumulasi di permukaan padatan yang disebut adsorben. Proses adsorpsi cocok untuk air limbah dengan logam konsentrasi rendah dan industri dengan keterbatasan biaya (Gupta dan Bhattacharyya, 2008; Salem dan Sene, 2011; Yuan dan Liu, 2013).

Salah satu tantangan dari teknologi adsorpsi adalah pemilihan alternatif adsorben yang ekonomis dan efisien untuk meminimalisir biaya operasi di negara berkembang (Yusoff dkk., 2014). Tanah liat telah menarik perhatian untuk mengadsorpsi logam berat dalam air yang terkontaminasi dengan biaya rendah (Sari dkk., 2007; Bhattacharyya dan Gupta, 2008; Ali dkk., 2012). Tanah liat merupakan aluminium silikat hidroksida yang membentuk fraksi koloid $(<2 \mu \mathrm{m})$ dari tanah, sedimen, batuan dan air. Tanah liat memiliki luas permukaan yang besar, kestabilan fisik dan mekanis, struktur lapisan teratur, kapasitas penukaran kation (cation exchange capacity) yang besar, sehingga tanah liat merupakan material yang baik sebagai adsorben (Tanabe 1981; Pinnavaia 1983, Gupta dan Bhattacharyya, 2008).

Pada penelitian sebelumnya banyak melakukan studi untuk mengetahui kemampuan adsorpsi logam oleh tanah liat murni. Montmorillonite dan kaolinite telah digunakan sebagai adsorben untuk menyisihkan timbal, cadmium, dan nikel (Srivastava, 1989; Veli dan Alyuz, 2007; Gupta dan Bhattacharyya, 2008). Kapasitas adsorpsi dari timbal dan cadmium lebih besar pada montmorillonite $(\mathrm{Pb}=0,68 ; \mathrm{Cd}=0,72 \mathrm{mg} / \mathrm{g})$ dibandingkan pada kaolinite $(\mathrm{Pb}=0,12 ; \mathrm{Cd}=0,32 \mathrm{mg} / \mathrm{g})$
(Veli dan Alyuz, 2007). Penelitian oleh Gupta dan Bhattacharyya (2008) menyatakan bahwa kapasitas adsorpsi yang didapatkan sesuai dengan isoterm Langmuir dimana $\mathrm{Pb}$ (II), Cd (II) dan Ni (II) adalah pada rentang 6,8-11,5 mg/g (dengan kaolinite) dan 21,1-31,1 mg/g (dengan montmorillonite). Tanah liat jenis kaolin telah digunakan sebagai adsorben untuk menyerap logam timbal $(\mathrm{Pb})$, didapatkan nilai qe untuk $\mathrm{Pb}$ oleh kaolin murni sebesar 5,2 mg/g dan untuk kaolin teraktivasi asam sebesar 6,3 mg/g.

Meskipun data mengenai kemampuan adsorpsi tanah liat sudah cukup banyak (Adebowale dkk., 2006; Bhattacharyya dan Gupta, 2006; Etci dkk., 2010; Salem dan Sene, 2011), sampai saat ini belum banyak studi yang dilakukan mengenai potensi pemakaian adsorben dari tanah liat yang didaur ulang. Adsorben daur ulang yang banyak diteliti berkisar pada adsorben berbasis karbon aktif (Gupta dan Ali, 2004; Sahu dkk., 2013; Yuan dan Liu, 2013).

Perbedaan penelitian ini dengan penelitian sebelumnya yaitu tanah liat yang digunakan sebagai adsorben berasal dari limbah industri keramik PT.X. Limbah tanah liat berasal dari proses pembentukan (shaping) keramik sebelum tanah liat mengalami proses pengeringan (drying). Hal ini dapat meningkatkan nilai fungsi dari limbah tanah liat sebagai adsorben logam berat. Konsep zero waste dan rendahnya biaya pengolahan ini merupakan keuntungan dari penggunaan limbah tanah liat sebagai adsorben. Penelitian ini dilakukan dalam skala laboratorium untuk mencari $\mathrm{pH}$, dosis adsorben, dan waktu kontak yang paling efektif untuk menurunkan kandungan logam berat pada limbah glasir, sehingga memenuhi baku mutu. Baku mutu yang digunakan yaitu Peraturan Mentri Lingkungan Hidup Nomor 16 Tahun 2008 tentang Baku Mutu Air Limbah Bagi Usaha dan/atau Kegiatan Industri Keramik. Pada peraturan ini baku mutu untuk logam, yaitu $\mathrm{Pb}$ (1 $\mathrm{mg} / \mathrm{L})$, Co (0,6 mg/L), Cd (0,1 mg/L) dan Cr (1 $\mathrm{mg} / \mathrm{L})$. Berdasarkan baku mutu ini kadar logam $\mathrm{Pb}$ pada limbah industri keramik di atas kadar yang ditetapkan sehingga perlu dilakukan pengolahan agar kadarnya sesuai dengan baku mutu yang telah ditetapkan.

\section{METODE PENELITIAN}

Pada studi ini, tanah liat sebagai adsorben dan air limbah yang mengandung logam berat sebagai adsorbat berasal dari limbah tanah liat industri keramik PT. X, yaitu industri keramik skala menengah yang memproduksi tableware dan dekorasi. Limbah tanah liat yang digunakan sebagai adsorben dihasilkan dari proses pembentukan (shaping) keramik sebelum tanah liat mengalami proses pengeringan (drying). Sedangkan, limbah glasir industri keramik dari PT. X sendiri digunakan sebagai adsorbat. Pemeriksaan terdahulu menunjukkan bahwa kandungan logam berat yang terkandung dalam air limbah tersebut cukup tinggi, yaitu $\mathrm{Pb} 1,2 \mathrm{mg} / \mathrm{L} ; \mathrm{Zn} \mathrm{7,0} \mathrm{mg/L;} \mathrm{Cd} \mathrm{0,013}$ mg/L dan Cu 0,033 mg/L. Limbah glasir ini dihasilkan 
dari proses pewarnaan keramik. Sampel limbah glasir yang diambil dari tempat pengumpulan limbah cair proses glasir kemudian ditempatkan pada lemari pendingin dengan suhu $4^{\circ} \mathrm{C}$ sebelum dipreparasi untuk tahap selanjutnya.

\section{Karakterisasi dan Preparasi Adsorben}

Tanah liat tidak dimodifikasi secara kimiawi agar dapat menghasilkan adsorben dengan biaya rendah. Tanah liat hanya dipanaskan di oven dengan suhu $105^{\circ} \mathrm{C}$ selama 48 jam kemudian disaring menggunakan saringan nomor 100 ASTM (150 $\mu \mathrm{m})$ (Mobavu, 2011). Kandungan kimiawi dari tanah liat tersebut dikarakterisasi sebelum percobaan adsorpsi dengan menggunakan X-Ray Diffraction Shimadzu XRD-7000 di Laboratorium Universitas Islam Negeri Jakarta. Kemudian morfologi permukaan dari adsorben sebelum dan sesudah proses adsorpsi diamati dengan menggunakan Scanning Electron Microscope FE-SEM FEI INSPECT F50 dan komposisi logam diamati dengan Energy Dispersive X-Ray EDAX EDS Analyzer di Laboratorium Uji Departemen Teknik Metalurgi dan Material, Universitas Indonesia.

\section{Batch Adsorpsi, Variasi pH, Dosis Adsorben dan Waktu Kontak}

Percobaan batch adsorpsi dilakukan pada suhu ruang, yaitu $25^{\circ} \mathrm{C}$. Pada percobaan, tanah liat yang telah dipreparasi dimasukan sebanyak 0,5 gram (kecuali pada variasi dosis adsorben) sebagai adsorben dalam 250 ml labu erlenmeyer dan ditambahkan 100 ml sampel glasir industri keramik. $\mathrm{pH}$ awal larutan adalah 8. Larutan tersebut diberikan beberapa perlakuan, diantaranya variasi $\mathrm{pH}$, dosis adsorben dan waktu kontak.

Variasi pH yang dilakukan adalah 6, 8 dan 12, dengan menambahkan 0,1 $\mathrm{M} \mathrm{NaOH}$ atau $0,1 \mathrm{M} \mathrm{HCl}$ untuk menyesuaikan variasi $\mathrm{pH}$ tersebut. Rentang $\mathrm{pH}$ tersebut didasarkan pada beberapa penelitian terdahulu yang dilakukan oleh Etci dkk. (2009), Bhattacharyya dan Gupta (2006), serta Veli dan Alyuz (2007) menyatakan bahwa $\mathrm{pH}$ optimum dalam mengadsorpsi logam dengan tanah liat adalah lebih dari 6. Parameter $\mathrm{pH}$ diukur dengan $\mathrm{pH}$ meter merek Eutech menggunakan metode SNI 06-6989.11-24. Setelah didapatkan $\mathrm{pH}$ optimum, variasi dosis adsorben yang dilakukan adalah 5, 10, 15, 20, dan 25 g/L. Setelah didapatkan $\mathrm{pH}$ dan dosis adsorben optimum, variasi waktu kontak yang dilakukan adalah 15, 30, 60, 90 dan 120 menit. Setiap perlakuan variasi, larutan diletakkan pada shaker (range kecepatan 0-200 rpm) diputar dengan kecepatan 150 rpm selama 60 menit (kecuali untuk variasi waktu kontak) kemudian disentrifugasi dengan alat sentrifugasi 80-2B (range kecepatan 0-4000 rpm) kecepatan 4000 rpm selama 10 menit.

\section{Karakterisasi dan Preparasi Adsorbat}

Sampel limbah glasir sebagai adsorbat dianalisa sebelum dan sesudah adsorpsi. Sebelum dilakukan pengukuran, sampel limbah glasir dipreparasi terlebih dahulu. Sampel sebanyak $50 \mathrm{ml}$ dimasukan ke dalam beaker glass $100 \mathrm{ml}$, kemudian ditambahkan $5 \mathrm{ml}$ $\mathrm{HNO}_{3}(\mathrm{p})$ serta 3-5 batu didih dan ditutup dengan cover glass. Larutan tersebut dipanaskan dengan hotplate pada suhu $150^{\circ} \mathrm{C}$ hingga volume sampel \pm 25 $\mathrm{ml}$, setelah itu didinginkan hingga mencapai suhu ruang. Jika sampel belum jernih, ditambahkan $5 \mathrm{ml}$ $\mathrm{HNO}_{3}$ (p) kemudian didinginkan dan disaring dengan filter 0,45 mikron ke dalam labu ukur $100 \mathrm{ml}$ kemudian ditambahkan air suling hingga tera. Pengukuran logam berat yang terkandung pada sampel diukur dengan menggunakan Atomic Absorption Spectroscopy (AAS) di Laboratorium Teknik Lingkungan, Departemen Teknik Sipil, Universitas Indonesia sesuai dengan metode SNI 06-6989.8-2004 untuk logam $\mathrm{Pb}$ dan SNI 06-6989.7-2004 untuk logam Zn (Sdiri dkk, 2012).

\section{Analisis dan Pengolahan Data}

Untuk mengetahui persentase penyisihan konsentrasi logam $\mathrm{Pb}$ dan $\mathrm{Zn}$ digunakan persamaan (1) dimana $\mathrm{C}_{o}$ adalah konsentrasi logam berat awal $(\mathrm{mg} / \mathrm{L})$ dan $\mathrm{C}_{\mathrm{e}}$ adalah konsentrasi logam berat pada kesetimbangan setelah diadsorpsi (mg/L).

$$
\text { Penurunan konsentrasi }=\frac{\mathrm{C}_{0}-\mathrm{C}_{\mathrm{e}}}{\mathrm{C}_{0}} \times 100 \%
$$

Isoterm Langmuir dan Freundlich digunakan untuk mengetahui sifat adsorpsi dari adsorben yang digunakan terhadap adsorbat. Pada isoterm Langmuir, diasumsikan adsorpsi yang terjadi membentuk lapisan tunggal (monolayer) serta semua situs dan permukaannya bersifat homogen. Persamaan isoterm Langmuir sebagai berikut

$$
\mathrm{q}_{\mathrm{e}}=\frac{\mathrm{v}_{\mathrm{m}} \mathrm{KC}_{\mathrm{e}}}{1+\mathrm{KC}_{\mathrm{e}}}
$$

dimana $\mathrm{q}_{\mathrm{e}}$ merupakan konsentrasi adsorbat teradsorpsi dalam setiap gram adsorben (mg/g); $\mathrm{C}_{\mathrm{e}}$ adalah konsentrasi logam berat setelah diadsorpsi (mg/L); K adalah konstanta dan $\mathrm{V}_{\mathrm{m}}$ merupakan kapasitas monolayer (Veli dan Alyuz, 2007).

Pada isoterm Freundlich diasumsikan adsorpsi yang terjadi membentuk lapisan monolayer dari molekul-molekul adsorbat pada permukaan adsorben namun situs-situs aktif pada permukaan adsorben bersifat heterogen. Persamaan isoterm Freundlich sebagai berikut

$$
\mathrm{q}_{\mathrm{e}}=\mathrm{K}_{\mathrm{f}} \mathrm{C}_{\mathrm{e}}^{1 / \mathrm{n}}
$$

dimana $\mathrm{q}_{\mathrm{e}}$ adalah konsentrasi adsorbat teradsorpsi dalam setiap gram adsorben (mg/g); Ce adalah konsentrasi logam berat setelah diadsorpsi; $\mathrm{K}_{\mathrm{f}}$ merupakan konstanta Freundlich dan 1/n adalah intensitas adsorpsi (Veli dan Alyuz, 2007).

\section{HASIL DAN PEMBAHASAN}

Kandungan kimia tanah liat sebagai adsorben pada Tabel 1 menunjukkan bahwa adsorben mengandung kaolinite $\left(\mathrm{Al}_{2}\left(\mathrm{Si}_{2} \mathrm{O}_{5}\right)(\mathrm{OH})_{4}\right)$ yang mempunyai kemampuan untuk mengikat kation 
sehingga dapat digunakan sebagai adsorben dalam adsorpsi logam. Namun demikian, pada tanah liat ini terdapat pengotor dalam jumlah yang cukup besar, yaitu quartz. Berdasarkan hasil pengukuran XRD dapat dilihat bahwa kandungan quartz mendominasi sedangkan kandungan kaolinitenya sebesar 28,4\%. Pada tanah liat terdapat pengotor dalam jumlah yang cukup besar, hal ini mungkin bisa menjadi salah satu penyebab berkurangnya daya adsorpsi dari adsorben. Adanya pengotor pada permukaan adsorben dapat menghalangi adsorbat untuk masuk ke dalam pori adsorben dan berinteraksi dengan adsorben. Pada limbah tanah liat yang digunakan sebagai adsorben juga terdapat kandungan lain selain kaolinite seperti kation organik, yang dapat berkompetisi dengan logam untuk memperebutkan sisi aktif adsorben sehingga mengakibatkan pengurangan kemampuan adsorpsi logam (Cruz-Guzman dkk., 2006).

Kandungan kaolinite yang relatif rendah dibandingkan kandungan quartz pada adsorben ternyata tetap dapat menghasilkan kualitas adsorpsi yang sesuai kebutuhan. Hasil adsorpsi logam dengan menggunakan tanah liat daur ulang dengan variasi $\mathrm{pH}$ antara 6, 8, dan 12 dan dosis adsorben 5-25 mg/L serta waktu kontak 15-120 menit disajikan pada Tabel 2. Dari hasil tersebut, dapat dilihat bahwa penyisihan logam berat dari air limbah meningkat dengan peningkatan $\mathrm{pH}$. Hal ini dikarenakan semakin meningkatnya $\mathrm{pH}$ maka meningkat pula sisi aktif adsorben yang berguna dalam mengikat logam (Bhattacharyya dan Gupta, 2008). Meningkatnya pH mengurangi konsentrasi $\mathrm{H}^{+}$sehingga mengurangi kompetisi antara ion logam dan proton dalam proses adsorpsi pada permukaan partikel (Adebowale dkk., 2006).

Tabel 1. Variasi pH pada proses adsorpsi logam $\mathrm{Pb}$ dan Zn

\begin{tabular}{ccc}
\hline \multirow{2}{*}{$\mathrm{pH}$} & \multicolumn{2}{c}{ Kadar logam $(\mathrm{mg} / \mathrm{L})$} \\
\cline { 2 - 3 } & $\mathrm{Pb}$ & $\mathrm{Zn}$ \\
\hline Kadar awal & 2.288 & 2.943 \\
6 & 1.996 & 2.602 \\
8 & 1.22 & 2.423 \\
12 & 0.886 & 2.297 \\
\hline
\end{tabular}

Penyisihan logam paling optimum didapatkan pada $\mathrm{pH} 12$ dengan kadar $\mathrm{Pb}$ yang sudah memenuhi baku mutu. Penyisihan $\mathrm{Pb}$ dan $\mathrm{Zn}$ yang melonjak pada pH 12 dapat disebabkan oleh 2 mekanisme, yaitu adsorpsi dan juga presipitasi pada saat yang bersamaan. Menurut Stumm dan Morgan (1996), pada pH 12, kelarutan $\mathrm{Pb}$ dan Zn serta kesetimbangan spesi hidroksida dan karbonat dari $\mathrm{Pb}$ dan $\mathrm{Zn}$ akan bergeser ke arah padatan. Adanya mekanisme presipitasi ini dapat memberikan hasil penyisihan maksimum, dibandingkan dengan proses adsorpsi pada $\mathrm{pH} 8$ dimana kadar $\mathrm{Pb}$ pada limbah setelah adsorpsi adalah 1,20 mg/L. Kadar tersebut masih berada di atas baku mutu yaitu $1 \mathrm{mg} / \mathrm{L}$. Namun, pemilihan $\mathrm{pH}$ dilakukan bukan berdasarkan penyisihan maksimum, namun berdasarkan $\mathrm{pH}$ optimum dimana kondisi percobaan yang diharapkan bukanlah untuk mencapai kadar $\mathrm{Pb}$ dan Zn yang dapat memenuhi baku mutu, namun lebih diarahkan untuk $\mathrm{pH}$ bagi percobaan dosis dan waktu kontak optimum selanjutnya. Untuk itu, pH 8 dianggap cukup baik karena penyisihan $\mathrm{Pb}$ sudah mencapai $47 \%$ dan penyisihan $\mathrm{Zn}$ sudah mencapai $17 \%$. Selain itu, larutan tidak perlu disesuaikan keasamannya karena $\mathrm{pH} 8$ adalah $\mathrm{pH}$ campuran adsorben dan adsorbat sebelum penyesuaian. Pada $\mathrm{pH}$ ini, pengolahan limbah glasir tidak membutuhkan pengaturan $\mathrm{pH}$ sehingga mengurangi biaya pengolahan limbah untuk memenuhi Peraturan Menteri Negara Lingkungan Hidup Nomor 16 Tahun 2008 tentang Baku Mutu Air Limbah Bagi Kegiatan Usaha dan/atau Kegiatan Industri Keramik, dimana baku mutu untuk pH limbah adalah 6-9.

Pada studi ini, pH yang dipakai berkisar pada rentang yang cenderung lebih basa dibandingkan rentang $\mathrm{pH}$ yang pada umumnya digunakan pada percobaan adsorpsi logam berat yaitu pH 3-6. Hal ini dilakukan berdasarkan dua pertimbangan utama, yaitu karena percobaan ini dilakukan untuk pemenuhan kadar logam berat terhadap baku mutu pemerintah dan bukan mencari efisiensi adsorpsi maksimum. Selain itu, kadar awal logam $\mathrm{Pb}$ dan $\mathrm{Zn}$ tidak terlalu tinggi dibandingkan dengan baku mutu pemerintah sehingga kebutuhan penyisihan logam tidak terlalu banyak. Meskipun pada pH yang cenderung basa dapat memicu penyisihan logam berat melalui mekanisme presipitasi, namun karena kadar logam yang tidak terlalu tinggi pada percobaan ini akan kecil kemungkinannya menyebabkan presipitasi, khususnya pada pH 8, sehingga untuk diskusi selanjutnya, mekanisme penyisihan lewat presipitasi dapat diabaikan dan diskusi selanjutnya akan dibahas sebagai proses adsorpsi.

Tabel 2. Kandungan adsorben tanah liat dengan XRD

\begin{tabular}{cccc}
\hline & Silikon oksida (quartz) & $\begin{array}{c}\text { Silicon } \\
\text { oksida }\end{array}$ & $\begin{array}{c}\text { Aluminum silikat hidroksida } \\
\text { (kaolinite) }\end{array}$ \\
\hline Formula & $\mathrm{SiO}_{2}$ & $\mathrm{SiO}_{2}$ & $\mathrm{Al}_{2}\left(\mathrm{Si}_{2} \mathrm{O}_{3}\right)(\mathrm{OH})_{4}$ \\
Total number of Peaks & 28 & 198 & 198 \\
Peaks in range & 21 & 198 & 158 \\
Peaks matched & 19 & 54 & 53 \\
Intensity scale factor & 1 & 0,06 & 0,14 \\
Quantity (weight \%) & 68,55 & 3,06 & 28,4 \\
\hline
\end{tabular}


Selanjutnya, $\quad \mathrm{pH} \quad 8$ digunakan untuk menentukan dosis adsorben dan waktu kontak optimum sehingga kadar logam $\mathrm{Pb}$ dan $\mathrm{Zn}$ dapat memenuhi baku mutu yang telah ditetapkan. Hasil percobaan variasi dosis disajikan pada Gambar 1.

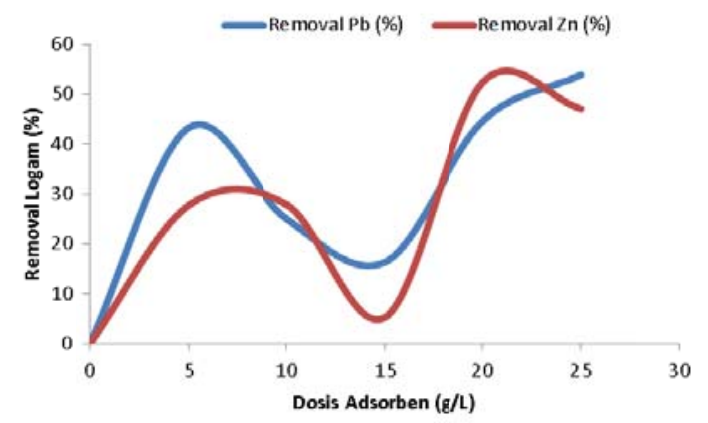

(a)

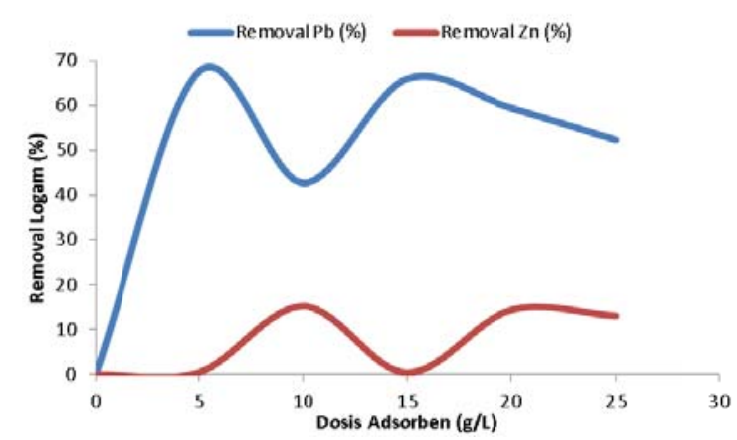

(b)

Gambar 1. Grafik pengaruh dosis adsorben dengan $\mathrm{pH}$ 8 dan waktu kontak 15 menit pada (a) Percobaan 1 dengan kadar awal logam $\mathrm{Pb}$ 1,4 mg/L dan Zn 4,3 mg/L; (b) Percobaan 2 kadar awal logam Pb 2,3 mg/L dan Zn 2,9 mg/L

Berdasarkan hasil percobaan, dapat dilihat bahwa semakin banyak dosis adsorben tidak berbanding lurus dengan penurunan kadar logam $\mathrm{Pb}$ dan Zn pada air limbah. Percobaan ini kemudian diulang kembali dengan kondisi awal air limbah yang berbeda dan hasil tetap didapatkan dengan tren yang serupa. Dari kedua percobaan tersebut, dapat disimpulkan bahwa dengan dosis adsorben yang rendah, yaitu sebesar $5 \mathrm{mg} / \mathrm{L}$, penyisihan logam berlangsung dengan cukup baik. Hal ini terlihat dengan konsentrasi logam terserap per satuan adsorben $\left(\mathrm{C}_{\mathrm{e}}\right)$ yang cukup tinggi pada dosis adsorben $5 \mathrm{~g} / \mathrm{L}$ dibandingkan dengan dosis adsorben lain. Peningkatan dosis pada kisaran 10-15 g/L tidak meningkatkan efisiensi adsorpsi, sedangkan peningkatan adsorpsi baru terjadi kembali pada kisaran dosis 20-25 g/L. Hal ini dapat disebabkan oleh adsorben tanah liat yang digunakan untuk mengadsorpsi logam yang dapat mengandung pengotor termasuk $\mathrm{Pb}$ dan $\mathrm{Zn}$ yang mungkin menambahkan logam pada larutan teradsorpsi. Namun demikian, penyisihan logam tetap terjadi bagi semua dosis sehingga unsur pengotor pada tanah liat merupakan salah satu kompromi kecil yang dapat diabaikan dibandingkan dengan konsep zero waste yang diterapkan.

Berdasarkan hasil dari dua percobaan yang telah dilakukan maka ditetapkan dosis optimum yang digunakan adalah $5 \mathrm{~g} / \mathrm{L}$. Hal ini hampir setara dengan penelitian yang dilakukan oleh Sahu dkk. (2013) yang menyatakan bahwa dosis adsorben optimum berupa limbah lumpur merah dari industri alumunium dalam mengadsorpsi logam $\mathrm{Pb}$ dengan kadar awal $10 \mathrm{mg} / \mathrm{L}$ pada $\mathrm{pH}$ 7,2 dan waktu kontak 30 menit adalah 0,4 $\mathrm{g} / 100 \mathrm{~mL}$ atau setara dengan $4 \mathrm{~g} / \mathrm{L}$. Begitu pula dengan dosis optimum adsorben berupa limbah lumpur penjernihan dari industri baja dalam mengadsorpsi logam $\mathrm{Pb}$ dengan kadar awal $10 \mathrm{mg} / \mathrm{L}$ dengan pH 5 dan waktu kontak 60 menit adalah 5 g/L (Naiya dkk., 2009). Namun, hal ini berbeda dengan penelitian yang menggunakan adsorben kaolinite murni. Gupta dan Bhattacharyya (2008) menyatakan bahwa dosis adsorben optimum berupa kaolin dalam mengadsorpsi logam $\mathrm{Pb}$ adalah 2 g/L. Proses adsorpsi yang menggunakan adsorben daur ulang di studi ini tentunya akan membutuhkan jumlah adsorben yang lebih banyak karena permukaan aktif yang berkurang dan tingginya kandungan quartz. Namun demikian, jumlah adsorben yang dibutuhkan hanya berkisar di 23 kali lipat sehingga pemakaian adsorben daur ulang masih tergolong efisien.

Pembubuhan adsorben tanah liat pada dosis 5 g/L membuat kadar logam $\mathrm{Pb}$ dan $\mathrm{Zn}$ di air limbah telah memenuhi baku mutu. Berdasarkan Peraturan Menteri Negara Lingkungan Hidup Nomor 16 Tahun 2008, kadar maksimum logam $\mathrm{Pb}$ adalah sebesar 1 mg/L. Pada dosis adsorben 5 g/L di percobaan 1 dan 2 diketahui kadar $\mathrm{Pb}$ setelah diadsorpsi berturut-turut adalah $0,816 \mathrm{mg} / \mathrm{L}$ dan $0,742 \mathrm{mg} / \mathrm{L}$ dengan persentase penyisihan berturut-turut 43,4\% dan 67,7\%. Sedangkan untuk Zn berturut-turut adalah 3,088 mg/L dan $2,928 \mathrm{mg} / \mathrm{L}$ dengan persentase penyisihan berturut-turut $27,8 \%$ dan $0,53 \%$. Hasil tersebut telah memenuhi baku mutu berdasarkan Keputusan Menteri Negara Lingkungan Hidup Nomor 51 Tahun 1995 tentang Baku Mutu Limbah Cair Bagi Kegiatan Industri Untuk Logam Zn yaitu 5 mg/L)

\section{Waktu Kontak Optimum}

Untuk mendapatkan kondisi pengolahan air limbah yang optimum, penentuan waktu kontak optimum perlu dilakukan, tentu dengan $\mathrm{pH}$ dan dosis adsorben optimum yang telah didapatkan sebelumnya. Pada waktu kontak 15 menit, kadar logam Pb pada larutan teradsorpsi adalah $0,614 \mathrm{mg} / \mathrm{L}$ dengan persentase penyisihan sebesar $61 \%$. Sedangkan untuk logam Zn, waktu kontak optimum adalah 60 menit dengan kadar logam Zn pada larutan teradsorpsi adalah 1,609 mg/L dan persentase penyisihan sebesar $30 \%$. Hal ini serupa dengan penelitian yang dilakukan oleh Sahu dkk. (2013) yang menyatakan bahwa waktu kontak optimum adsorpsi logam $\mathrm{Pb}$ dengan limbah lumpur merah dari industri alumunium adalah 10 
menit dengan persentase penyisihan mencapai $88 \%$. Sedangkan waktu kontak optimum adsorpsi logam Zn dengan adsorben berupa sedimen sungai adalah 60 menit dengan persentase penyisihan mencapai 85\% (Jain, 2004).

Berbeda dengan penelitian yang dilakukan oleh Adebowale dkk. (2006) yang menyatakan bahwa waktu kontak optimum adsorpsi logam $\mathrm{Pb}$ dengan kaolin dimodifikasi dan tidak dimodifikasi berturutturut adalah 8 dan 20 menit dengan persentase penyisihan adalah 94,8\% dan 78,7\%. Sari dkk. (2007) juga mendapatkan waktu optimum adsorpsi logam $\mathrm{Pb}$ dengan tanah jenis kaolin adalah 30 menit dengan pesentase penyisihan mencapai 98\%. Selain disebabkan karena perbedaan jenis kaolin yang digunakan sebagai adsorben, perbedaan konsentasi awal adsorbat (dalam hal ini adalah logam $\mathrm{Pb}$ ) yang akan diadsorpsi juga menjadi penyebab perbedaan waktu kontak optimum yang didapatkan.

Dalam menentukan waktu kontak optimum untuk proses adsorpsi, pertimbangan yang diambil adalah penyisihan logam dan efisiensi unit proses PT. $\mathrm{X}$ yang menghasilkan limbah glasir dalam jumlah sedikit sehingga dapat dibuat pengolahan secara mekanis dengan sistem batch. Waktu kontak yang digunakan dalam mendesain pengolahan limbah glasir di industri keramik PT. X ini tidak mempengaruhi ukuran bak adsorpsi karena pelaksanaan adsorpsi dilakukan berdasarkan metode batch setiap beberapa bulan. Namun tentunya, waktu kontak tetap mempengaruhi efektivitas biaya energi yang digunakan dalam pengadukan oleh impeller. Oleh karena itu, penulis mengambil waktu kontak optimum 15 menit. Pada waktu kontak ini, kadar logam $\mathrm{Pb}$ dan Zn sudah memenuhi baku mutu yang telah ditetapkan.

\section{Isoterm Adsorpsi}

Mekanisme adsorpsi ditentukan dengan mengevaluasi keseimbangan data adsorpsi yang diperoleh dari percobaan. Hubungan kesetimbangan antara jumlah logam yang diadsorpsi oleh adsorben dapat ditunjukan melalui adsorpsi isoterm (Bulut dkk., 2008). Mekanisme adsorpsi berdasarkan isoterm Langmuir dan Freundlich untuk logam $\mathrm{Pb}$ dan $\mathrm{Zn}$ disajikan pada Tabel 3. Dari persamaan linear isoterm Langmuir pada gambar maka didapatkan nilai kapasitas monolayer $\left(\mathrm{V}_{\mathrm{m}}\right)$ dan konstanta Langmuir (k). Sedangkan dari persamaan logaritma isoterm Freundlich pada gambar maka didapatkan nilai konstanta Freundlich $\left(\mathrm{K}_{\mathrm{f}}\right)$.

Meskipun Isoterm Langmuir memiliki koefisien korelasi yang cukup baik, namun kedua isotherm tersebut kurang dapat dipakai untuk menjelaskan fenomena adsorpsi yang terjadi. Dari hasil percobaan didapatkan kapasitas monolayer maksimum dalam mengadsorpsi logam $\mathrm{Pb}$ dan $\mathrm{Zn}$ berturut-turut adalah 0,013 dan 0,043 mg/g tanah liat sebagai adsorben. Hasil ini cukup berbeda jika dibandingkan dengan penelitian yang dilakukan oleh Adebowale dkk. (2006) yang menyatakan bahwa kapasitas monolayer kaolin dalam mengadsorpsi logam $\mathrm{Pb}$ mencapai 19,27 mg/g. Begitu pula pada penelitian Sari dkk. (2007), kapasitas monolayer kaolin yang didapatkan dalam mengadsorpsi logam $\mathrm{Pb}$ adalah 31,75 mg/g. Penelitian Etci dkk. (2009), pada temperatur $25^{\circ} \mathrm{C}$, kapasitas monolayer kaolin bahkan mencapai $83,33 \mathrm{mg} / \mathrm{g}$. Nilai $\mathrm{R}^{2}$ pada ketiga penelitian tersebut mencapai 0,99. Hal ini disebabkan karena pada penelitian tersebut jenis kaolin yang digunakan merupakan kaolin murni dan juga adsorbat yang digunakan adalah limbah cair buatan. Sedangkan limbah cair yang digunakan pada penelitian ini adalah limbah glasir serta adsorben yang digunakan merupakan daur ulang limbah tanah liat yang bersumber dari industri keramik yang tidak dapat dihindari kemungkinan terdapat ion logam selain $\mathrm{Pb}$ dan $\mathrm{Zn}$ yang dapat menjadi kompetitor dalam proses adsorpsi.

Tabel 3. Mekanisme adsorpsi isoterm Langmuir dan Freundlich untuk logam $\mathrm{Pb}$ dan Zn dengan limbah glasir pada percobaan 1

\begin{tabular}{|c|c|c|c|c|c|c|c|c|c|c|c|c|}
\hline \multirow[t]{2}{*}{ Logam } & \multirow{2}{*}{$\begin{array}{c}\text { Variasi } \\
\text { dosis } \\
\text { adsorben } \\
(\mathrm{g} / \mathrm{L})\end{array}$} & \multirow{2}{*}{$\begin{array}{c}\text { Kadar } \\
\text { Ce } \\
(\mathrm{mg} / \mathrm{L})\end{array}$} & \multirow{2}{*}{$\begin{array}{l}\text { Penyisihan } \\
\text { (\%) }\end{array}$} & \multirow{2}{*}{$\begin{array}{c}\mathrm{q}_{\mathrm{e}} \\
(\mathrm{mg} / \mathrm{g})\end{array}$} & \multicolumn{3}{|c|}{ Langmuir } & \multicolumn{5}{|c|}{ Freundlich } \\
\hline & & & & & $\mathrm{C}_{\mathrm{e}} / \mathrm{q}_{\mathrm{e}}$ & $\mathrm{R}^{2}$ & $\begin{array}{l}\text { Pers. } \\
\text { linier }\end{array}$ & $\begin{array}{c}\mathrm{Vm} \\
(\mathrm{mg} / \mathrm{g}\end{array}$ & $\begin{array}{c}\text { Log } \\
\mathrm{C}_{\mathrm{e}} / \mathrm{q}_{\mathrm{e}}\end{array}$ & $\mathrm{R}^{2}$ & $\begin{array}{l}\text { Pers. } \\
\text { linier }\end{array}$ & $\begin{array}{c}\mathrm{K}_{\mathrm{f}} \\
(\mathrm{mg} / \mathrm{g})\end{array}$ \\
\hline \multirow[t]{6}{*}{$\mathrm{Pb}$} & $\begin{array}{c}\text { Kadar } \\
\text { awal }\end{array}$ & 1,441 & & & & \multirow{6}{*}{0,624} & \multirow{6}{*}{$\begin{array}{c}y= \\
94,12 x \\
-54,05\end{array}$} & & & \multirow{6}{*}{0,217} & \multirow{6}{*}{$\begin{array}{c}y= \\
0,138 \\
\ln (x)+ \\
0,982\end{array}$} & \multirow{6}{*}{9,594} \\
\hline & 5 & 0,816 & 43,373 & 0,125 & 21,364 & & & 0,013 & 6,528 & & & \\
\hline & 10 & 1,08 & 25,052 & 0,036 & 24,821 & & & & 29,917 & & & \\
\hline & 15 & 1,205 & 16,378 & 0,016 & 6,528 & & & & 76,589 & & & \\
\hline & 20 & 0,798 & 44,622 & 0,032 & 29,917 & & & & 24,821 & & & \\
\hline & 25 & 0,664 & 53,921 & 0,031 & 76,589 & & & & 21,364 & & & \\
\hline \multirow[t]{6}{*}{ Zn } & $\begin{array}{c}\text { Kadar } \\
\text { awal }\end{array}$ & 4,277 & & & & \multirow{6}{*}{0,632} & \multirow{6}{*}{$\begin{array}{c}y= \\
109,8 x \\
-248,6\end{array}$} & \multirow{6}{*}{0,043} & & \multirow{6}{*}{0,347} & \multirow{6}{*}{$\begin{array}{c}\mathrm{y}= \\
0,457 \\
(\ln ) \mathrm{x}+ \\
2,512\end{array}$} & \multirow{6}{*}{325,087} \\
\hline & 5 & 3,088 & 27,807 & 0,238 & 18,174 & & & & 12,981 & & & \\
\hline & 10 & 3,083 & 27,914 & 0,119 & 28,064 & & & & 25,825 & & & \\
\hline & 15 & 4,050 & 5,314 & 0,015 & 25,825 & & & & 267,298 & & & \\
\hline & 20 & 2,036 & 52,391 & 0,112 & 12,981 & & & & 18,174 & & & \\
\hline & 25 & 2,262 & 47,113 & 0,081 & 267,298 & & & & 28,064 & & & \\
\hline
\end{tabular}


Pada percobaan, dosis optimum telah dilakukan beberapa kali dan menunjukkan tren yang sama yaitu penambahan dosis adsorben tidak selalu berbanding lurus dengan penurunan kadar logam berat. Hal ini dikarenakan adsorben berasal dari limbah yang memungkinkan terdapat banyak pengotor yang dapat berkompetisi dengan logam untuk memperebutkan sisi aktif adsorben sehingga mengakibatkan pengurangan kemampuan adsorpsi logam. Berdasarkan alasan diatas, maka meskipun menunjukan $\mathrm{R}^{2}$ yang tidak mendekati 1 , percobaan dapat dianggap valid karena adsorben yang bertambah tidak selalu berbanding lurus dengan daya adsorpsi logam, karena adsorben yang digunakan berasal dari limbah. Selain itu, karena menggunakan limbah, maka ada kemungkinan di adsorben juga terdapat pengotor lain termasuk logam.

Pada penelitian Yussof dkk. (2014), kapasitas adsorpsi logam $\mathrm{Pb}$ dengan menggunakan adsorben daur ulang seperti serbuk kayu pohon durian yaitu 20,37 mg/g, sabut kelapa yaitu 2,76 mg/g dan tandan kelapa sawit yaitu 4,48 mg/g. Pada penelitian Sahu dkk. (2013), kapasitas adsorpsi logam Pb dengan menggunakan adsorben daur ulang dari limbah lumpur merah yang berasal dari industri alumunium yaitu 6,0273 mg/g. Selain itu, Gupta dan Ali (2004) mendapatkan kapasitas adsorpsi logam $\mathrm{Pb}$ dengan menggunakan adsorben daur ulang berupa fly ash dari limbah industri gula yaitu 2,50 mg/g. Perbedaan kapasitas ini tidak terlalu signifikan jika dibandingkan dengan kapasitas yang didapatkan pada penelitian ini. Perbedaan tersebut kemungkinan disebabkan oleh perbedaan jenis dan karakteristik dari adsorben yang digunakan. Selain itu, perbedaan kemungkinan juga disebabkan karena kondisi lingkungan saat proses adsorpsi seperti pH, temperatur, waktu kontak, dosis/konsentrasi logam sebelum adsorpsi dan dosis adsorben. Berdasarkan adsorpsi isoterm maka didapatkan data pengurangan logam $\mathrm{Zn}^{2+}<\mathrm{Pb}^{2+}$. Hasil ini sesuai dengan percobaan Baker dkk. (2008) dimana didapatkan hasil adsorpsi $\mathrm{Zn}^{2+}<\mathrm{Cu}^{2+}<\mathrm{Cd}^{2+}$

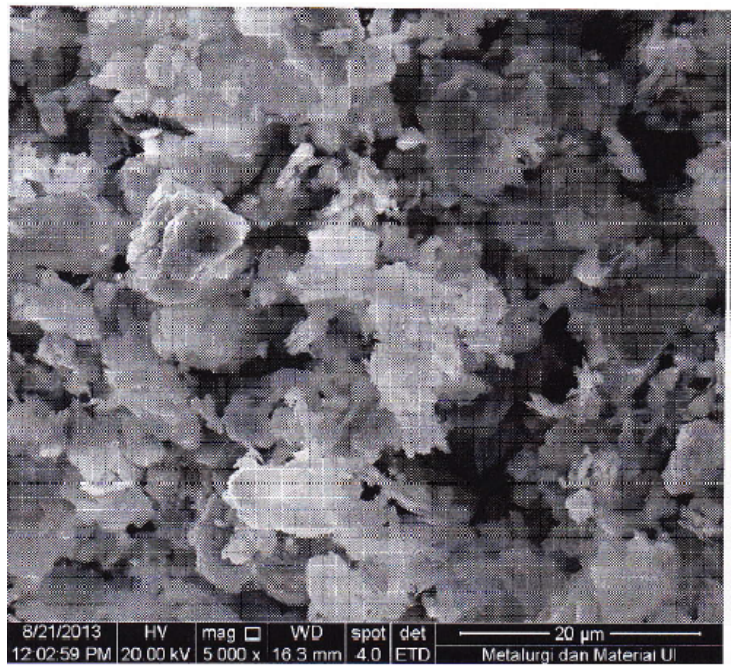

(a)
$<\mathrm{Pb}^{2+}$. Kation timbal membentuk senyawa kompleks stabil dengan oksigen yang terdapat pada tanah liat. Selain itu, energi hidrasi timbal lebih lemah dibandingkan dengan seng $(-1,481 \mathrm{~kJ} / \mathrm{mol}$ dan $-2,406$ $\mathrm{kJ} / \mathrm{mol}$ untuk $\mathrm{Pb}$ dan $\mathrm{Zn}$ secara berurutan) sehingga seng lebih memiliki afinitas tinggi untuk air.

\section{Karakterisasi Adsorben Teradsorpsi Adsorbat}

Karakteristik morfologi adsorben sebelum dan setelah teradsorpsi adsorbat dengan kondisi optimum, yaitu $\mathrm{pH}$ 8, dosis adsorben $5 \mathrm{~g} / \mathrm{L}$ dan waktu kontak 15 menit, disajikan pada Gambar 2. Karakteristik morfologi ini dilakukan dengan analisis Scanning Electron Microscopy (SEM). Analisis SEM berguna untuk mengobservasi tampak morfologi permukaan dari adsorben sebelum dan sesudah adsorpsi logam (Yusoff dkk., 2014). Terlihat pada Gambar 2, tanah liat sebagai adsorben sebelum dan sesudah teradsorpsi logam Pb pada magnifikasi 5000 kali.Tidak tampak perubahan morfologi pada permukaan tanah liat sebagai adsorben sesudah proses. Hal ini menunjukkan bahwa proses presipitasi logam yang terjadi tidak signifikan. Proses adsorpsi ini diperkuat dengan hasil analisis Energy Dispersive X-Ray (EDX) yang didapatkan pada tanah liat sebelum dan sesudah teradsorpsi (lihat Tabel 4). Berdasarkan hasil analisis EDX, terdeteksi keberadaan logam $\mathrm{Pb}$ yang meningkat secara signifikan pada tanah liat setelah proses adsorpsi. Proses adsorpsi dengan menggunakan adsorben daur ulang ini terlihat lebih efektif untuk penyisihan logam $\mathrm{Pb}$ dibandingkan dengan logam $\mathrm{Zn}$. Selain terlihat dari hasil analisa AAS, hal ini juga dapat dilihat dari hasil EDX yang tidak menemukan logam Zn pada adsorben karena kadarnya yang berada di bawah batas pengukuran. Selain itu, dari hasil EDX ini dapat dilihat bahwa terjadi peningkatan $\mathrm{Na}$ dan $\mathrm{Ca}$ setelah proses adsorpsi sebesar dengan kisaran 2-3\% dan 5-6\%. Peningkatan Na dan $\mathrm{Ca}$ ini dapat terjadi melalui proses adsorpsi namun juga secara presipitasi.

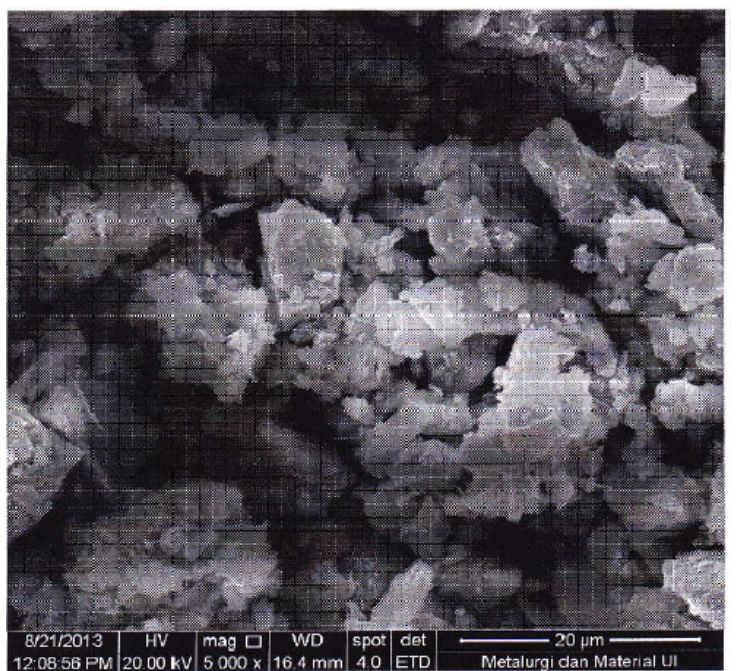

(b)

Gambar 2. Tampak morfologi permukaan adsorben (a) Sebelum teradsorpsi; (b) Setelah teradsorpsi dengan SEM 
Tabel 4. Komposisi tanah liat sebelum adsorpsi dengan EDX (pengukuran triplo untuk sampel yang sama)

\begin{tabular}{|c|c|c|c|c|c|c|c|c|c|c|c|c|c|}
\hline \multicolumn{7}{|c|}{ Komposisi tanah liat sebelum adsorpsi } & \multicolumn{7}{|c|}{ Komposisi tanah liat setelah adsorpsi } \\
\hline Test & $\mathrm{O}(\%)$ & $\begin{array}{l}\mathrm{Na} \\
(\%)\end{array}$ & $\begin{array}{c}\mathrm{Al} \\
(\%)\end{array}$ & Si (\%) & $\begin{array}{c}\mathrm{K} \\
(\%)\end{array}$ & $\begin{array}{c}\mathrm{Ca} \\
\text { (\%) }\end{array}$ & $\mathrm{O}(\%)$ & $\begin{array}{c}\mathrm{Na} \\
(\%)\end{array}$ & $\begin{array}{c}\mathrm{Al} \\
(\%)\end{array}$ & Si (\%) & $\begin{array}{c}\mathrm{Pb} \\
(\%)\end{array}$ & $\begin{array}{c}\mathrm{K} \\
(\%)\end{array}$ & $\begin{array}{c}\mathrm{Ca} \\
\text { (\%) }\end{array}$ \\
\hline 1 & 56,95 & 1,54 & 6,91 & 31,90 & 1,65 & 1,06 & 53,11 & 5,20 & 0,96 & 25,37 & 5,32 & 1,77 & 8,27 \\
\hline 2 & 53,82 & 3,87 & 9,11 & 30,59 & 1,84 & 0,78 & 48,88 & 5,42 & 1,98 & 24,06 & 11,7 & 2,16 & 5,78 \\
\hline 3 & 56,78 & 2,10 & 5,91 & 32,83 & 1,76 & 0,62 & 55,88 & 4,39 & 1,86 & 24,12 & 4,85 & 1,46 & 7,43 \\
\hline
\end{tabular}

Bak Multifungsi (Penyimpanan + Proses)

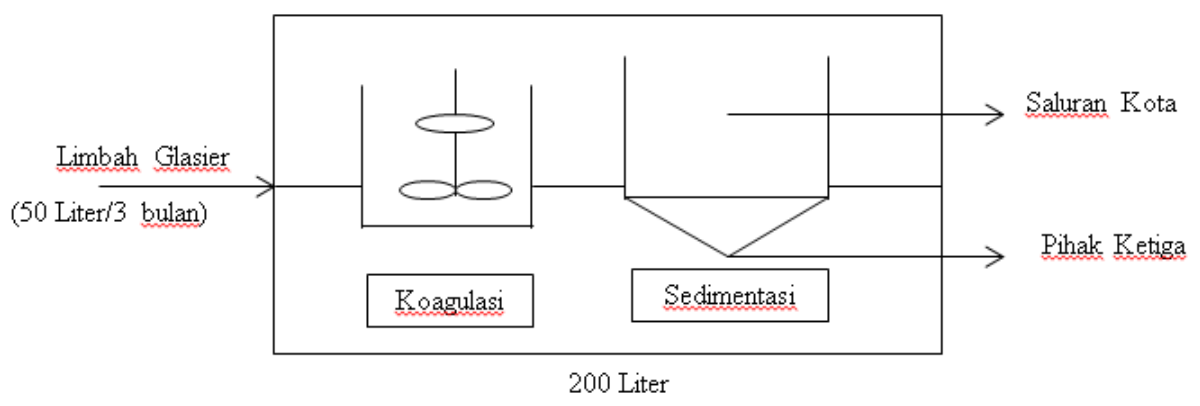

Gambar 3. Rancangan diagram pengolahan limbah

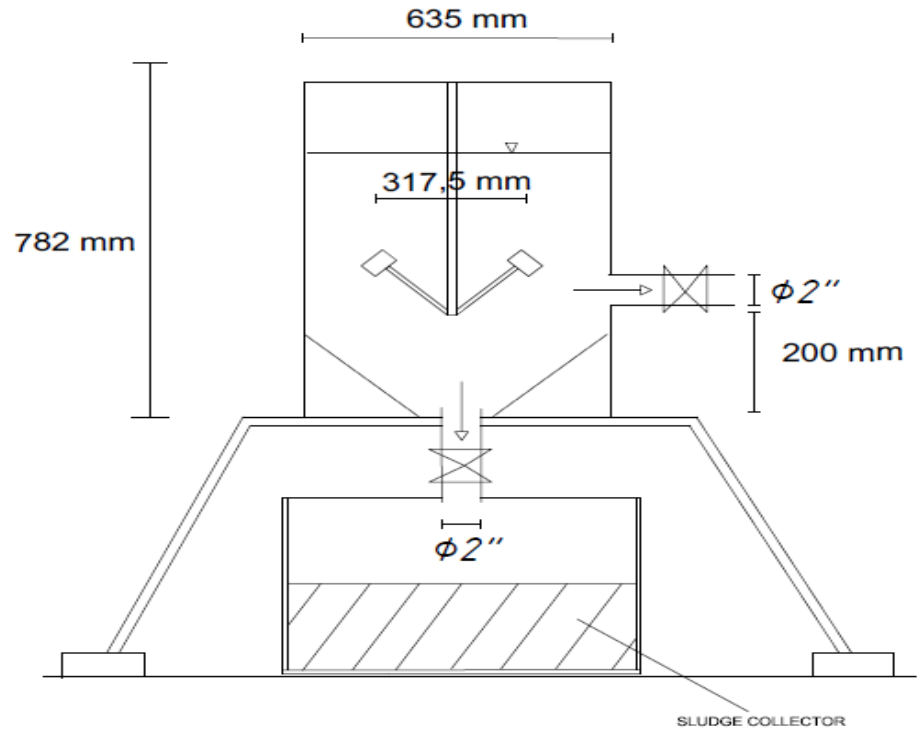

Gambar 4. Desain pengolahan limbah glasir indutri keramik

\section{Desain Unit Pengolahan Limbah Cair pada Industri Keramik PT. X}

Desain unit pengolahan limbah cair pada industri keramik PT.X didasarkan pada data hasil percobaan skala laboratorium yang telah dilakukan. Limbah yang dihasilkan dapat ditampung dalam bakbak penyimpanan. Pada desain ini akan dibuat tangki multifungsi dengan kapasitas maksimum 200 liter (Gambar 3). Tangki multifungsi ini berguna sebagai tangki penyimpanan dan pemrosesan limbah glasir. Limbah glasir yang dihasilkan oleh industri keramik PT. X akan ditampung selama 3 bulan, baru kemudian dilakukan pengolahan. Limbah glasir ditampung selama 3 bulan dengan mempertimbangkan efektivitas pengolahan karena limbah glasir yang dihasilkan industri ini sangat kecil dan juga tidak stabil berdasarkan proses produksi yang tergantung kepada permintaan konsumen. Selain itu, waktu penampungan yang lama tidak akan menimbulkan dampak yang buruk karena kadar organik dan zat volatil yang rendah.

Adsorben yang digunakan diambil dari limbah tanah liat yang dihasilkan oleh industri kemudiandipanaskan pada oven dengan suhu $105^{\circ} \mathrm{C}$ selama 48 jam. Setelah tanah liat kering kemudiantanah liat disaring menggunakan saringan berukuran $150 \mu \mathrm{m}$. dosis adsorben yang diberikan pada limbah glasir adalah berdasarkan hasil analisa skala laboratorium yaitu $5 \mathrm{~g} / \mathrm{L}$.

Limbah glasir kemudian akan diolah secara mekanis menggunakan impeller dengan kecepatan pengadukan $150 \mathrm{rpm}$ selama 15 menit. Setelah diaduk selama 15 menit, limbah glasir akan didiamkan di dalam tangki untuk kemudian mengalami proses 
sedimentasi. Selama proses sedimentasi, limbah akandidiamkan kurang lebih selama 6 jam. Padatan akan mengendap di bawah sedangkan bagian supernatant dapat dibuang menggunakan pipa langsung ke saluran kota dekat pabrik. Lumpur hasil pengolahan akan diserahkan ke pihak ketiga karena lumpur banyak mengandung logam berat yang berpindah. Pihak ketiga yang dimaksud merupakan pihak yang telah memiliki izin dari pemerintah untuk mengolah limbah B3. Pada industri ini tidak dibuat pengolahan lumpur karena akan membutuhkan banyak biaya untuk mengolah lumpur dan lumpur yang dihasilkan oleh industri ini juga jumlahnya sedikit. Hal ini dikarenakan volume limbah glasir yang dihasilkan pada PT. X kecil. Pada bagian bawah tangki akan disediakan bak penampung lumpur untuk menampung lumpur yang dihasilkan.

\section{KESIMPULAN}

Berdasarkan hasil penelitian dapat disimpulkan bahwa tanah liat daur ulang dari industri keramik tableware dapat dipakai sebagai adsorben logam berat dari limbah glasir keramik tersebut. Didapatkan data yaitu pada $\mathrm{pH}$ 8, dosis adsorben $5 \mathrm{~g} / \mathrm{L}$ dan waktu kontak selama 15 menit merupakan kondisi efektif dalam menyisihkan logam $\mathrm{Pb}$ dan $\mathrm{Zn}$ agar memenuhi baku mutu. Adsorben dari tanah liat yang mengandung 28,4\% kaolinite dapat menyisihkan sekitar 44\% logam $\mathrm{Pb}$ dan 23\% logam Zn. Dari hasil penelitian ini, kadar logam $\mathrm{Pb}$ dan $\mathrm{Zn}$ yang terkandung pada limbah yang teradsorpsi telah memenuhi baku mutu yang telah ditetapkan oleh Kementerian Lingkungan Hidup, yaitu $1 \mathrm{mg} / \mathrm{L}$ untuk $\mathrm{Pb}$ dan 5 mg/L untuk Zn.

\section{UCAPAN TERIMA KASIH}

Ucapan terima kasih ditujukan kepada Teknik Penyehatan Lingkungan, Departemen Teknik Sipil, Universitas Indonesia serta Sri Diah H.S dan Licka Kamadewi sebagai laboran; Laboratorium Uji Departemen Teknik Metalurgi dan Material, Universitas Indonesia; Laboratorium Universitas Islam Negeri; serta kepada PT. X yang telah memberikan sampel limbah cair industri untuk dapat diuji.

\section{DAFTAR PUSTAKA}

Adebowale, K.O., Unuabonah, I.E., and Olu-Owolabi, B. I., (2006), The Effect of Some Operating Variables on The Adsorption of Lead and Cadmium Ions on Kaolinite Clay, Journal of Hazardous Materials B134, pp. 130-139.

Ali, I., Asim, M., and Khan, T.A., (2012), Low Cost Adsorbents for The Removal of Organic Pollutants from Wastewater, Journal of Environmental Management 113, 170-183.

Baker, H. M., Massadeh, A.M., and Younes, H.A., (2008), Natural Jordanian zeolite: removal of heavy metal ions from water samples using column and batch methods, Environmental Monitoring and Assessment 157(1-4), pp. 319-330.

Bhattacharyya, K.G. and Gupta, S.S., (2006), Pb (II) Uptake by Kaolinite and Montmorillonite in Aqueous Medium-Influence of Acid Activation of The Clays, Colloids and Surfaces A: Physicochem. Eng Aspect 277, pp. 191-200.

Bhattacharyya, K.G. and Gupta, S.S., (2008), Adsorption of a few heavy metals on natural and Modified Kaolinite and Montmorillonite : A Review, Advances in Colloid and Interface Science 140, pp. 114-131.

Bulut, E., Ozacar, M., and Sengil, I.A., (2008), Equilibrium and Kinetic Data and Process Design for Adsorption of Congo Red on Bentonite, Journal of Hazardous Materials 154, pp. 613-622.

Cruz-Guzman, M., R.Celiz, Hermosin, M., Koskinen, W., Nater, E., and Cornejo, C., (2006), Heavy Metal Adsorption by Montmorilonites Modified with Natural Organic Cations, Soil Science Society of America Journal 70, pp. 215-221.

Etci, O., Bektas, N., and Oncel, M.S., (2010), Single and Binary Adsorption of Lead and Cadmium Ions from Aqueous Solution Using The Clay Mineral Beidellite, Environ Earth Sci 61, pp. 231-240.

Gupta, S.S. and Bhattacharyya, K.G., (2008), Immobilization of $\mathrm{Pb}$ (II), Cd (II) and Ni (II) Ions on Kaolinite and Montmorillonite Surfaces from Aqueous Medium, Journal of Environmental Management 87, pp. 46-58.

Gupta, V.K. and Ali, I., (2004), Removal of Lead and Chromium from Wastewater Using Bagasse Fly Ash a Sugar Industry Waste, J. Col. Int.Sci. 271, 321-328.

IPCC, (2006), Ceramic Manufacturing Industry, European Commission: Directorate-General Joint Research Center.

Jain, D.S., (2004), Adsorption of Zinc on Bed Sediment of River Hindon : Adsorption Models and Kinetics, Journal Hazard Mater, pp. 231-239.

Jang-Soon, K., Seong-Taek, Y., Jong-Hwa, L., SoonOh, K., and Ho-Young, J., (2010), Removal of Divalent Heavy Metals (Cd, Cu, Pb, and $\mathrm{Zn}$ ) and Arsenic (III) from Aqueous Solutions Using Scoria : Kinetics and Equilibria of Sorption, Journal of Hazardous Materials 174, pp. 307-313.

Mahitti, U.F., (2008), Preparation and Use of Chemically Modified MCM-41 and Silica Gel as Selective Adsorbent for Hg (II) Ions, Journal Hazard Mater 154, pp. 578-587. 
Menteri Lingkungan Hidup, (2008), Peraturan Menteri Lingkungan Hidup No. 16 Tahun 2008 tentang Baku Mutu Air Limbah Bagi Kegiatan Usaha dan/atau Kegiatan Industri Keramik, Indonesia: Kementerian Lingkungan Hidup.

Mobavu, B., (2011), Brine Treatment Using Natural Adsorbents, Cape: University of The Western Cape.

Naiya, T.K., Bhattacharya, A.K., and Das, S.K., (2009), Clarified Sludge (Basic Oxygen Furnace Sludge) - an Adosrbent for Removal of Pb (II) from Aqueous Solutions - Kinetics, Thermodynamics and Desoption Studies, Journal of Hazardous Materials 170 , pp. 252-262.

Pinnavia, T.J., (1983), Intercalated Clay Catalysis, Science 220, pp. 365-371.

Sahu, M.K., Mandal, S., Dash, S.S., Badhai, P., and Patel, R.K., (2013), Removal of Pb (II) from Aqueous Solution by Acid Activated Red Mud, Journal of Environmental Chemical Engineering 1, pp. 13151324.

Salem, A. and Sene, R.A., (2011), Removal of Lead from Solution by Combination of Natural ZeoliteKaolin-Bentonite as a New Low Cost Adsorbent, Chemical Engineering Journal 174, 619-628.

Sari, A., Tuzen, M., Citak, D., and Soylak, M., (2007), Equilibrium, Kinetic and Thermodynamic Studies of Adsorption of $\mathrm{Pb}$ (II) from Aqueous Solution onto Turkish Kaolinite Clay, Journal of Hazardous Materials 149, pp. 283-291.

Sdiri, A., Higashi, T., Chaabouni, R., dan Jamoussi, F., (2012), Competitive Removal of Heavy Metals from Aqueous Solutions by Montmorillonitic and Calcareous Clays, Water Air Soil Pollut, pp. 11911204.

Stumm, W. and Morgan, J., (1996), Aquatic Chemistry: Chemical Equilibria and Rates in Natural Waters, Wiley-Interscience 3rd edition.

Sundari, K.N., (2009), Pembuatan Glasir Kelabu Dengan Menggunakan Pencampuran Bahan Pewarna Biru dan Hijau, Jurnal Sains dan Teknologi Indonesia Vol. 11 , hal. 90-94.

Tanabe, K., (1981), Solid Acid and Base Catalysis, In : Anderson, J.R., Boudart, M. (Eds). New York: Spinger.

TWG, C., (2005), Merged and Sorted Comments Master Spread Sheet. Applied Clay Science.

Veli, S. and Alyuz, B., (2007), Adosprtion of Copper and Zinc from Aqueous Solutions by Using Natural Clay, Journal of Hazardous Materials 149, pp. 226233.

Yuan, L. and Liu, Y., (2013), Removal of Pb (II) and Zn (II) from Aqueous Solution by Ceramisite Prepared by Sintering Bentonite, Iron Powder and Activated Carbon. Chemical Engineering Journal 215-216, pp. 432-439.

Yusoff, S. N., Kamari, A., Putra, W.P., Ishak, C.F., Mohamed, A., Hashim, N., and Isa, M.I., (2014), Removal of $\mathrm{Cu}$ (II), $\mathrm{Pb}$ (II) and $\mathrm{Zn}$ (II) Ions from Aqueous Solutions Using Selected Agricultural Wastes : Adsorption and Characterisation Studies, Journal of Environmental Protection Vol. 5, pp. 289300 . 